suspected the organism may be identified more rapidly by analysis of the usually foul smelling pus by GLC.

Ashington Hospital, West View,

P. R. CROOK

Ashington, Northumberland

PHLS and Microbiology Laboratory,

J. GRAY

Hartshill Road,

Stoke-on-Trent

\title{
References
}

1 Dodd M J, Grifiths I D, Freeman R. Pyogenic arthritis due to bacteroides complicating rheumatoid arthritis. Ann Rheum Dis 1982; 41: 248-9.

2 Crook P R, Gray J. Acute osteomyelotis of the clavicle due to Bacteroides fragilis. North Staffordshire Medical Institute Journal 1981; 13: 66-7.

3 Raff M J, Melo J C. Anaerobic osteomyelitis. Medicine (Baltimore) 1978; 57: 83-103.

4 Brook I, Reza M J, Bricknell K S, Bluestone R, Finegold S M. Abnormalities in synovial fluid of patients with septic arthritis detected by gas-liquid chromatography. Ann Rheum Dis 1980; 39: $168-72$.

\section{Calciferal levels in RA and OA}

SIR, We were interested to read the report of Bird et al. demonstrating no significant difference in 1 , 25-dihydroxycholecalciferol levels $\left(1,25(\mathrm{OH})_{2} \mathrm{D}_{3}\right)$ in a group of patients with rheumatoid arthritis (RA) compared with a similar group with osteoarthritis (OA). ${ }^{1}$

We have demonstrated a general increase in bone turnover as measured by whole body retention (WBR) ${ }^{2}$ of $99 \mathrm{~m}$ technetium methylene diphosphonate in rheumatoid patients compared with matched controls. ${ }^{3}$ Serum levels of vitamin $D$ metabolites including $1,25(\mathrm{OH})_{2} \mathrm{D}_{3}$ were normal in 8 patients whose WBR was elevated. This lends additional support to the concept of a generalised as well as a periarticular abnormality of bone turnover in RA which occurs as part of the inflammatory disease process.

Rheumatic Diseases Centre, University of Manchester, Salford M6 8HD

\section{References}

1 Bird H A, Wright B, Hennes U, Theiss E. Comparison of serum 1, 25-dihyloroxycholecalciferol concentrations in rheumatoid arthritis and osteoarthrosis. Ann Rheum Dis 1982; 41: 257-8.

2 Fogelman I, Bessent R G, Turner J G, Critin D L, Boyle I T, Greig WR. The use of whole-body-retention of ${ }^{99 m}$ Tc diphosphonate in the diagnosis of metabolic bone disease. J Nucl Med Allied Sci 1977; 19: 170-275.

3 Rajapakse C, Thompson R n, Grennan D M, et al. Increased bone metabolism in rheumatoid arthritis as measured by the whole body retention of ${ }^{99 m}$ Tc methylene diphosphonate. Ann Rheum Dis in press.

\section{Streptococci and reactive arthritis}

SIR, We were interested to read the case report of Hubbard and Hughes. ${ }^{1}$ There are some similarities between their patient and the one we described in $1980 .^{2}$ A $43-$ year-old salesman developed, 3 weeks after a throat infection due to beta-haemolytic streptococci, predominant lower limbs arthritis, low back pain, and severe talalgia.

In the presence of subcutaneous nodules, pericardial effusion, and a previous history of rheumatic fever at the age of 19 an acute attack of rheumatic fever was diagnosed. The ASO titre was $1600 \mathrm{U} / \mathrm{ml}$. In addition to these classical signs of rheumatic fever the patient sustained not only sacroiliac pain for 2 weeks but also a painful swelling of the right big toe and severe bilateral talalgia lasting more than 1 year, which evolved to calcaneal erosions. There were no yersinia agglutinins, and HLA B27 was positive.

It is interesting to note that both rheumatic fever and a reactive arthritis (considered as an incomplete form of Reiter's syndrome in our report) followed a streptococcal throat infection in this patient. The association of both conditions could be fortuitous. However, these data suggest, as in the case reported by our colleagues, that streptococci might be considered as one of the infectious agents capable of precipitating a reactive arthritis in an HLA B27-positive individual.

Centre Hospitalier,

J. C. GERSTER

Universitaire Vaudois,

M. PAYOT

1011 Lausanne,

Switzerland

G. RAPPOPORT

\section{References}

1 Hubbard W N, Hughes G R V. Streptococci and reactive arthritis. Ann Rheum Dis 1982; 41: 435.

2 Gerster J C, Payout M, Rappoport G. Probably fortuitous association of rheumatic fever and Reiter's syndrome. $Z$ Rheumatol 1980; 39: 343-7.

\section{Histocompatibility antigens in patients with ectopic ossification due to fibrodysplasia ossificans progressiva}

SIR, Sharpiro et al. ${ }^{1}$ have suggested that HLA B27 might have the effect of increasing liability to new bone formation. The basis for this was a claimed association between B27 and ankylosing hyperostosis, but, although the evidence is that there is no such association, we have taken the opportunity to study the HLA antigen frequencies in 23 patients from the UK with fibrodysplasia ossificans 